\title{
Knowledge and perceptions about malaria in communities in four districts of the Central African Republic
}

\author{
Gustave Bobossi Serengbe ${ }^{1,2}$, Jean-Methode Moyen ${ }^{3}$, Rosine Fioboy ${ }^{2}$, Edith Narcisse Beyam ${ }^{4}$, Cyriaque Kango ${ }^{2}$, \\ Colette Bangue ${ }^{2}$ and Alexandre Manirakiza ${ }^{5^{*}}$
}

\begin{abstract}
Background: Implementation of malaria control strategies may face major social and cultural challenges. Hence, understanding local knowledge about malaria helps in designing sustainable community-based malaria control programmes. We designed a pilot survey in communities in the Central African Republic to evaluate recognition of malaria symptoms, perceptions of the causes of malaria and knowledge of key preventive measures.

Methods: This cross-sectional study was conducted in four districts. Households were selected by multi-stage cluster random sampling, with villages (in Lobaye, Ouham and Ouaka) and boroughs (in Bangui City) as first-stage units and households as second-stage units. A total of 2920 householders were interviewed.

Results: Most of the respondents attributed malaria to mosquito bites (65.5\%), but less than $50 \%$ were familiar with the classical symptoms of malaria. Hygiene and sanitation were the most frequently mentioned methods for preventing malaria (81.1\%). Despite the relatively high rate of ownership of insecticide-treated nets (72.1\%), community perception of these nets as a preventive measure against mosquito bites was very low (6.5\%).

Conclusions: The correct perceptions that mosquitoes cause malaria transmission and of environmental management for prevention are encouraging; however, awareness about the usefulness of insecticide treated-nets for malaria prevention must be raised. This study provided the national malaria control programme with baseline data for planning appropriate health education in communities.
\end{abstract}

Keywords: Malaria, Knowledge, Community, Central African Republic

\section{Background}

Malaria is a major public health problem, especially for vulnerable groups such as children under 5 years and pregnant women in sub-Saharan Africa, where 90\% of malaria deaths occur [1,2]. In 1997, leaders at the annual meeting of the Organization of African Unity called for action to control malaria, and a global partnership to "roll back" malaria was initiated [3]. In 1998, the World Health Organization, the World Bank, the United Nations Development Programme and the United Nations Children's Fund formed the Roll Back Malaria (RBM) partnership. One of the aims of RBM is to provide all families with health information to ensure effective

\footnotetext{
* Correspondence: amanirak@yahoo.fr

${ }^{5}$ Institut Pasteur of Bangui, PO Box 923, Bangui, Central African Republic

Full list of author information is available at the end of the article
}

prevention and effective first-line treatment of malaria for young children [4].

The Abuja Declaration in 2000 called on all African Member States to commit themselves to reduce the malaria burden by half by the year 2010. The targets of the Declaration were reduction of the malaria burden by at least $60 \%$ and of overall mortality by $50 \%$, at least $60 \%$ of people with malaria having access to prompt treatment with antimalarial drugs and at least $60 \%$ of those at risk, particularly children under 5 and pregnant women, benefiting from community protective measures such as insecticide-treated nets [5]. The targets also include increasing the percentage of children with fever who receive adequate treatment and increasing the prevalence of use of bed nets by high-risk populations [6]. 
Implementation of malaria control strategies requires adequate synergy between service delivery and community response $[7,8]$. The strategies may face major social and cultural challenges that negatively influence the choice, acceptance and use of malaria control interventions [9-11]. A number of studies have been conducted about knowledge and perceptions relating to malaria in Africa, which found that misconceptions concerning malaria are still common [12-15]. Understanding local knowledge about malaria can help in designing sustainable community-based malaria control programmes that will lead to behavior change and adoption of new ideas and technology [11].

The Central African Republic (CAR) is a vast, sparsely populated country, covering $623000 \mathrm{~km}^{2}$ and with a population in 2006 of 4299502 inhabitants. The national malaria control programme implemented the first phase of RBM activities during the period before 2005-2009, which consisted of achieving significant health care coverage and sensitization of the population about preventive aspects. So far, no study on knowledge and perception about malaria has been conducted in the country. Hence, the present study was undertaken to assess recognition of malaria symptoms, perceptions about the causes of malaria and knowledge of preventive measures in the community.

\section{Method}

\section{Study area}

A survey was conducted during October 2009 in households in four districts, Lobaye, Ouham, Ouaka and Bangui City (Figure 1), selected by the National Division of Malaria Control as part of its efforts to assess achievement of the targets established for implementation of RBM activities.

The climate of the CAR is subequatorial, with a rainy period between April and November and temperatures

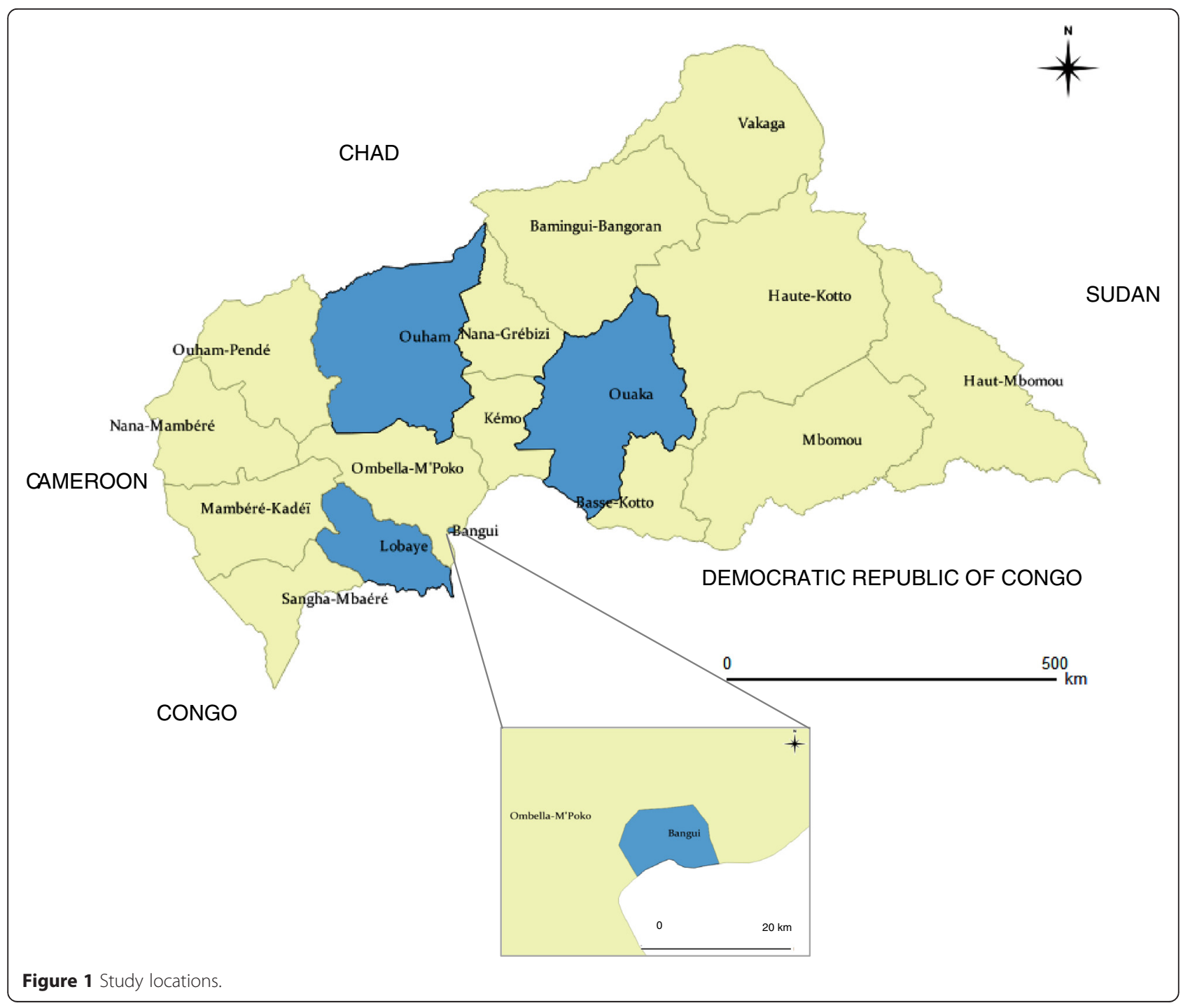


varying from $19^{\circ} \mathrm{C}$ to $32^{\circ} \mathrm{C}$. Malaria transmission is perennial; all areas of the country are exposed to endemic malaria, with a peak during the rainy season, although no data are available on the intensity of malaria transmission. Malaria accounts for more than $40 \%$ of morbidity in the country (CAR Ministry of Health, unpublished data). The activities of the national malaria programme consist of implementing RBM strategies to reduce morbidity and mortality related to malaria in the general population by reaching the coverage rate recommended in the Abuja Declaration [5].

\section{Training}

A team of 10 investigators received 12 days $(8 \mathrm{~h} /$ day $)$ of training in participant sampling techniques, conducting interviews and filling in questionnaires. A pilot survey was conducted to assess the validity of the questionnaire and the skills of the investigators in collecting information in an unselected region (Ombela M'Poko) during June 2009.

\section{Sample size and sampling procedure}

Households were selected by multi-stage cluster random sampling, with villages (in Lobaye, Ouham and Ouaka) and boroughs (in Bangui City) as first-stage units and households as second-stage units. In each region, we selected 30 villages or boroughs after probability proportional sampling based on the number of inhabitants. A list of villages (in Lobaye, Ouham and Ouaka) and boroughs (in Bangui City) and the population size of each area were obtained from the national census [16]. The formula $n=\left(d\left(z_{\alpha / 2}\right)^{2} p(1-p) / i^{2}\right.$ was used to calculate the sample sizes of householders required. Calculations were based on $50 \%(p)$ malaria prevention and treatment indicators [17], $z_{\alpha / 2}=1.96$, a $4 \%$ margin of error $(i)$, a design effect of $1.5(d)$ and a $20 \%$ non-response rate. Hence, a sample of 1035 householders was estimated for each region. Random selection of households was achieved with the following formula: 1035* $\left(H_{v} / H_{t}\right)$, where $H_{v}$ is the number of households in each village or borough and $H_{t}$ is the total number of households in the selected village or borough.

\section{Data collection and analysis}

The investigators were distributed as follows: three in Ouham, three in Ouaka, two in Bangui and two in Lobaye, who used cars or motorbikes to reach each survey point. The house of the village or borough chief was considered as the starting-point, and random direction by flipping a coin was used to select subsequent households for interview. A household was defined as the entity in which people live together and have a meal from a common cooking facility, and a householder was defined as the person who is perceived by members of household as the key decision-maker in the family [18]. Data on causes, symptoms and prevention of malaria were collected on a standard questionnaire during an interview constructed in French and translated into Sango (the local language). The questionnaire was in a closed-ended format, with some questions allowing open-ended answers.

The data collected were entered onto an Excel spreadsheet and analysed with SPSS software version 11. Descriptive statistics were used to measure frequencies and percentages of variables.

\section{Ethical approval and informed consent}

The study received ethical approval from the institutional review boards of the CAR Ministry of Health. Informed consent was obtained from all study participants. The heads of the communities were involved in population sensitization to participate in the survey.

\section{Results}

A total of 2920 householders were interviewed $(70.5 \%$ of the expected sample size). Table 1 shows the distribution of the study population according to region. Householders reported disparate perceptions of the causes and symptoms of malaria. Most attributed the disease to cold weather during the rainy season $(67.5 \%)$ and to mosquito bites (65.6\%); others associated malaria with intestinal worms (32.0\%), fatigue (3.7\%) and sorcerers or evil spirits (3.4\%). Most respondents in Bangui (79.7\%) and in Ouaka $(79.0 \%)$ attributed malaria to cold weather, while $73.3 \%$ of respondents believed that mosquito bites cause malaria transmission in Ouham, $72.0 \%$ in Ouaka, 63.3\% in Lobaye and 56.2\% in Bangui.

Abdominal pains, convulsions, yellowish urine and fever were the most frequently mentioned symptoms, reported by $65.1 \%, 44.9 \%, 40.3 \%$ and $39.1 \%$ of respondents, respectively.

Hygiene and sanitation were the most frequently mentioned methods for preventing malaria $(81.1 \%)$, while only $6.5 \%$ of participants believed that insecticide-treated nets provided protection from mosquito bites, although $72.1 \%$ of households reported that they had been given a net (Table 2).

\section{Discussion}

More than half the householders mentioned mosquito bites as the mode of malaria transmission. In malariaendemic areas, people are aware of the role of mosquito bites in the transmission of malaria; our result is lower than those reported in most studies from other subSaharan countries $[11,13,19,20]$, but higher than that reported by Paulander et al. [21] in Ethiopia and by Eyobo et al. [22] in Sudan. Our finding agrees with that reported by Singh et al. [23] in Nigeria. 
Table 1 Knowledge of respondents about the causes and symptoms of malaria according to survey site, Central Africa Republic, 2009

\begin{tabular}{|c|c|c|c|c|c|c|}
\hline & & Lobaye $(n=589)$ & Ouham $(n=731)$ & Ouaka $(n=685)$ & Bangui $(n=915)$ & All $(\mathrm{N}=2920)$ \\
\hline \multirow[t]{5}{*}{ Cause } & Mosquito bite & 63.3 & 73.3 & 72.0 & 56.2 & 65.5 \\
\hline & Cold weather & 59.6 & 48.0 & 79.0 & 79.7 & 67.5 \\
\hline & Intestinal worms & 35.0 & 43.2 & 20.1 & 29.9 & 32.0 \\
\hline & Fatigue & 1.4 & 4.7 & 3.5 & 4.6 & 3.7 \\
\hline & Sorcerer, evil spirits & 4.1 & 1.2 & 3.2 & 4.9 & 3.4 \\
\hline \multirow[t]{10}{*}{ Signs and symptoms } & Abdominal pain & 53.5 & 68.3 & 72.0 & 64.9 & 65.1 \\
\hline & Yellowish urine & 46.5 & 38.2 & 28.5 & 47.0 & 40.3 \\
\hline & Fever & 42.6 & 17.1 & 44.1 & 50.8 & 39.1 \\
\hline & Convulsions & 40.1 & 36.3 & 61.5 & 42.4 & 44.9 \\
\hline & Muscle pain & 20.4 & 45.4 & 27.2 & 37.3 & 33.5 \\
\hline & Diarrhoea & 24.4 & 13.8 & 29.6 & 26.0 & 23.5 \\
\hline & Chills & 6.3 & 6.7 & 6.4 & 12.3 & 8.3 \\
\hline & Pallor & 5.4 & 1.4 & 9.5 & 5.7 & 5.4 \\
\hline & Vomiting & 1.4 & 3.8 & 2.8 & 5.1 & 3.5 \\
\hline & Headache & 2.7 & 3.8 & 3.1 & 3.8 & 3.4 \\
\hline
\end{tabular}

Despite the relatively high level of awareness about the mode of malaria transmission, some people still believed that exposure to cold weather is a direct cause of malaria (malaria is known in Sango as kobela ti de or "cold disease"). The idea might have stemmed from the concurrence of cold, cloudy weather and the presence of mosquito breeding sites. The perception of respondents that intestinal worms and fatigue are causes of malaria is surprising, although fatigue could be related to symptoms of malaria, and, given the shared endemicity of malaria and soil-transmitted helminths, these diseases often co-exist in the same populations. Helminths may therefore be associated with a continued and possibly increased incidence of malaria infection [24-26]. This evidence corroborates the high rate of reporting of abdominal pain as a symptom of malaria. The socioanthropological belief of some respondents that malaria is associated with sorcery may be due to the belief in sub-Saharan Africa that convulsions (a symptom of severe malaria) are due to evil spirits [27].
The relatively low rate $(<50 \%)$ of respondents who were familiar with the classical symptoms of malaria is a cause for concern, because it may delay treatment. Other studies reported that respondents had good knowledge about malaria signs and symptoms $[18,23]$.

Substantial numbers of householders $(81.1 \%)$ were aware of the importance of hygiene and sanitation for malaria prevention. This finding corroborates those of other studies $[19,21]$. This is not surprising, because the message "maintaining environmental sanitation" is an important component of the malaria control programme [28-31], and this key sensitization aspect is frequently used in malaria prevention and control interventions in the CAR.

Despite the relatively high rate of ownership of an insecticide-treated net (72.1\%), the community perception of these nets as a preventive measure against mosquito bites was very low (6.5\%). This result is lower than those reported in other studies: $63.9 \%$ in the United Republic of Tanzania [32], 48.7\% in Cameroon [19], 46.2\% in Ethiopia [21] and 34.0\% in Sudan [22]. Adongo et al. [11] mentioned

Table 2 Ownership of insecticide-treated nets and knowledge about prevention of malaria according to survey site, Central Africa Republic, 2009

\begin{tabular}{|c|c|c|c|c|c|}
\hline Variable & Lobaye $(n=589)$ & Ouham $(n=731)$ & Ouaka $(n=685)$ & Bangui ( $n=915$ ) & All $(N=2920)$ \\
\hline Own an insecticide-treated net & 71.5 & 73.3 & 69.3 & 73.6 & 72.1 \\
\hline \multicolumn{6}{|c|}{ Knowledge of preventive measures } \\
\hline Hygiene and sanitation & 67.9 & 83.3 & 87.2 & 84.3 & 81.1 \\
\hline No insecticide-treated net & 10.0 & 19.2 & 15.4 & 14.7 & 13.1 \\
\hline Chloroquine & 3.6 & 7.7 & 17.9 & 17.6 & 12.0 \\
\hline Insecticide-treated net & 1.8 & 3.8 & 12.8 & 8.8 & 6.5 \\
\hline
\end{tabular}


awareness of the role of nets in malaria nuisance reduction but not in malaria prevention.

The main limitation of this study is the lack of data on socio-demographic status (age, sex and educational level), as it would be useful to test their influence on correct knowledge about malaria [21,33,34]. In the CAR, it has been argued that each region present its own challenges for implementation of the health programme because of cultural and socio-economic diversity, which is masked by national averages [35]. Hence, comparison of the findings from different study sites would be uninformative, as each locality has social and cultural specificities. Another limitation is that the expected sample size was not reached. The physical inaccessibility of some villages and boroughs due to scarce land transport was a serious constraint in this study.

\section{Conclusion}

This study provided the national malaria control programme with baseline data for planning appropriate health education in communities. The findings showed that perceptions of mosquito bites as the cause of malaria transmission and of environmental management for prevention are satisfactory; however, awareness about the use of insecticide-treated nets as a preventive measure against malaria was poor. Hence, emphasis on sensitizing communities about the use of insecticide treated-nets for malaria prevention is suggested. Core population coverage indicators for RBM are needed.

\section{Competing interests}

The authors declare that they have no competing interests.

\section{Authors' contributions}

All authors contributed to the design of the study or assisted with data interpretation. GBS was involved throughout the study, including design, data acquisition, analysis and interpretation of results and drafting the manuscript. JMM, SK, RF, ENB and CB supervised collection of data in the field. AM was involved in interpreting the results, analysing the data and writing the manuscript. All authors approved the final version.

\section{Acknowledgements}

We dedicate this paper to the memory of Dr François Banyombo, who unfortunately died a few months ago. He helped us greatly in this project. We wish to recognize Dr Marthe Inaïs Nsizoa and Dr Sylvie Vickos Mekongo for their contributions. The authors are also grateful to the data collection teams in Lobaye, Ouham, Ouaka and Bangui and to the householders for their cooperation in this study and for their compliance. They thank all the data managers, facilitators and participants for their constructive critical assistance during the validation meetings. We would like to thank Professor Elisabeth Heseltine for critically reviewing the manuscript and for comments and suggestions. This study was funded by the United Nations Development Programme through a grant from the Global Fund to Fight AIDS, Tuberculosis and Malaria (Project No. 00044846).

\section{Author details}

${ }^{1}$ University of Bangui, PO Box 1450, Bangui, Central African Republic. ${ }^{2}$ Complexe Pédiatrique de Bangui, Ministry of Public Health, Population and AIDS Control, PO Box 883, Bangui, Central African Republic. ${ }^{3}$ Malaria Programme Division, Ministry of Public Health, Population and AIDS Control, PO Box 883, Bangui, Central African Republic. ${ }^{4}$ United Nations Population
Fund, Bangui, PO Box 873, Bangui, Central African Republic. ${ }^{5}$ Institut Pasteur of Bangui, PO Box 923, Bangui, Central African Republic.

Received: 30 October 2014 Accepted: 15 April 2015

Published online: 19 April 2015

\section{References}

1. Dellicour S, Tatem AJ, Guerra CA, Snow RW, ter Kuile FO. Quantifying the number of pregnancies at risk of malaria in 2007: a demographic study. PLoS Med. 2010;7(1):e1000221.

2. Rowe AK, Rowe SY, Snow RW, Korenromp EL, Schellenberg JR, Stein C, et al. The burden of malaria mortality among African children in the year 2000. Int J Epidemiol. 2006;35(3):691-704.

3. Nabarro DN, Tayler EM. The "roll back malaria" campaign. Science. 1998;280(5372):2067-8

4. Narasimhan V, Attaran A. Roll back malaria? The scarcity of international aid for malaria control. Malar J. 2003;2:8

5. African Summit on Roll Back Malaria. The Abuja Declaration on Roll Back Malaria in Africa by the African Heads of State and Government. 25 April 2000. http://www.usaid.gov/sites/default/files/documents/1864/abuja.pdf (last accessed 6 August 2009).

6. Remme JH, Binka F, Nabarro D. Toward a framework and indicators for monitoring Roll Back Malaria. Am J Trop Med Hyg. 2001;64(1-2 Suppl):76-84.

7. Tyagi P, Roy A, Malhotra MS. Knowledge, awareness and practices towards malaria in communities of rural, semi-rural and bordering areas of east Delhi (India). J Vector Borne Dis. 2005:42(1):30-5.

8. World Health Organization. World malaria report. Geneva: 2008.

9. Ng'ang'a PN, Jayasinghe G, Kimani V, Shililu J, Kabutha C, Kabuage L, et al. Bed net use and associated factors in a rice farming community in central Kenya. Malar J. 2009;8:64.

10. Winch PJ, Makemba AM, Kamazima SR, Lwihula GK, Lubega P, Minjas JN, et al. Seasonal variation in the perceived risk of malaria: implications for the promotion of insecticide-impregnated bed nets. Soc Sci Med. 1994;39(1):63-75.

11. Adongo PB, Kirkwood B, Kendall C. How local community knowledge about malaria affects insecticide-treated net use in northern Ghana. Trop Med Int Health. 2005;10(4):366-78.

12. Wanzala P, Hassanali J, Kibet P, Dossajee H. Perceptions of primary health care with regard to corresponding knowledge, attitude and practices amongst the Kenyan Maasai. East Afr Med J. 2005;82(1):24-7.

13. Hlongwana KW, Mabaso ML, Kunene S, Govender D, Maharaj R. Community knowledge, attitudes and practices (KAP) on malaria in Swaziland: a country earmarked for malaria elimination. Malar J. 2009;8:29.

14. Govere J, Durrheim D, la Grange K, Mabuza A, Booman M. Community knowledge and perceptions about malaria and practices influencing malaria control in Mpumalanga Province, South Africa. S Afr Med J. 2000;90(6):611-6.

15. Mboera LE, Shayo EH, Senkoro KP, Rumisha SF, Mlozi MR, Mayala BK. Knowledge, perceptions and practices of farming communities on linkages between malaria and agriculture in Mvomero District, Tanzania. Acta Trop. 2010;113(2):139-44.

16. République Centrafricaine, Ministère de l'économie, du plan et de la coopération internationale, Direction générale de la statistique, des études économiques et sociales, Bureau central du recensement: Recensement Général de la Population et de l'Habitat, Bangui, 2003

17. UNICEF. Enquête à Indicateurs Multiples, MICS2000. Rapport Final Bangui. Bangui: Ministère du Plan; 2001. p. 130-1.

18. Ahmed SM, Haque R, Haque U, Hossain A. Knowledge on the transmission, prevention and treatment of malaria among two endemic populations of Bangladesh and their health-seeking behaviour. Malar J. 2009;8:173.

19. Kimbi HK, Nkesa SB, Ndamukong-Nyanga JL, Sumbele IU, Atashili J, Atanga MB. Knowledge and perceptions towards malaria prevention among vulnerable groups in the Buea Health District, Cameroon. BMC Public Health. 2014;14:883.

20. Enato EF, Okhamafe AO, Okpere EE. A survey of knowledge, attitude and practice of malaria management among pregnant women from two health care facilities in Nigeria. Acta Obstet Gynecol Scand. 2007;86(1):33-6.

21. Paulander J, Olsson H, Lemma H, Getachew A, San Sebastian M. Knowledge, attitudes and practice about malaria in rural Tigray, Ethiopia. Glob Health Action. 2009;2. doi: 10.3402/gha.v2i0.1839.

22. Eyobo MB, Awur AC, Wani G, Julla Al, Remijo CD, Sebit B, et al. Malaria indicator survey 2009, South Sudan: baseline results at household level. Malar J. 2014;13:45. 
23. Singh R, Musa J, Singh S, Ebere UV. Knowledge, attitude and practices on malaria among the rural communities in aliero, northern Nigeria. J Fam Med Prim Care. 2014;3(1):39-44.

24. Valencia CA, Fernandez JA, Cucunuba ZM, Reyes P, Lopez MC, Duque S. Correlation between malaria incidence and prevalence of soil-transmitted helminths in Colombia: an ecologic evaluation. Biomedica. 2010:30(4):501-8.

25. Alemayehu T, Ye-ebiyo Y, Ghebreyesus TA, Witten KH, Bosman A, Teklehaimanot A. Malaria, schistosomiasis, and intestinal helminths in relation to microdams in Tigray, northern Ethiopia. Parassitologia. 1998;40(3):259-67.

26. Basavaraju SV, Schantz P. Soil-transmitted helminths and Plasmodium falciparum malaria: epidemiology, clinical manifestations, and the role of nitric oxide in malaria and geohelminth co-infection. Do worms have a protective role in P. falciparum infection? Mt Sinai J Med. 2006;73(8):1098-105.

27. Okeke TA, Okafor HU, Uzochukwu BS. Traditional healers in Nigeria: perception of cause, treatment and referral practices for severe malaria. J Biosoc Sci. 2006;38(4):491-500.

28. Ghosh SK, Patil RR, Tiwari S, Dash AP. A community-based health education programme for bio-environmental control of malaria through folk theatre (Kalajatha) in rural India. Malar J. 2006;5:123.

29. Amoran OE, Onwumbe OO, Salami OM, Mautin GB. The influence of environmental sanitation on prevalence of malaria in a rural town in south-western Nigeria. Niger J Med. 2014;23(3):254-62.

30. Bamidele JO, Ntaji MI, Oladele EA, Bamimore OK. Community participation in malaria control in olorunda local government area, osun state, southwestern Nigeria. Afr J Infect Dis. 2012;6(2):24-8.

31. Keiser J, Singer $\mathrm{BH}$, Utzinger J. Reducing the burden of malaria in different eco-epidemiological settings with environmental management: a systematic review. Lancet Infect Dis. 2005:5(11):695-708

32. Mazigo HD, Obasy E, Mauka W, Manyiri P, Zinga M, Kweka EJ, et al. Knowledge, attitudes, and practices about malaria and its control in rural northwest Tanzania. Malar Res Treat. 2010;2010:794261.

33. van Geldermalsen AA, Munochiveyi R. Knowledge, attitude and practice (KAP) relating to malaria in Mashonaland Central, Zimbabwe. Cent Afr J Med. 1995;41(1):10-4.

34. Adedotun AA, Morenikeji OA, Odaibo AB. Knowledge, attitudes and practices about malaria in an urban community in south-western Nigeria. J Vector Borne Dis. 2010;47(3):155-9.

35. African Health Workforce Observatory. Profil pays en ressources humaines pour la santé (2010): Centrafrique. 2010

\section{Submit your next manuscript to BioMed Central and take full advantage of:}

- Convenient online submission

- Thorough peer review

- No space constraints or color figure charges

- Immediate publication on acceptance

- Inclusion in PubMed, CAS, Scopus and Google Scholar

- Research which is freely available for redistribution 